A more unlikely scene it is hardly possible to conceive; in fact, it is only necessary to place the facts before professional men, and they cannot but condemn the whole narrative as sensational in the extreme, and contrary to medical custom and etiquette in all civilised nations.

I fancy I hear the reader exclaim cui bono? Why allude to such nonsense? I reply, simply because Good Words is a most popular and influential magazine; it is extensively read, and to a very great extent it moulds the popular opinions of the day on a great variety of subjects-chloroform not excepted. It behoves us then to look alive and counteract this morbid influence, by each of us in his own sphere informing his friends and patients, as opportunity offers, that the whole tale told in it about chloroform is downright nonsense!

Will it be believed, that I have been informed in more quarters than one that Good Words is pledged to allow nothing into its pages that favours chloroform? I trust, for the sake of its excellent editor, that this report is false. In a conversation which I had with Professor Simpson the other day while in Edinburgh, we came upon the subject of the chloroform sensation scene in Good Words; and he said he had a good mind to ask Dr. Macleod to give him permission to write an article on chloroform for his magazine. If Dr. Simpson does so, we shall soon know "which way the wind blows."

Now for the "fruits of Good Words." I was lately consulted by a lady who had been suffering from fistula in ano for eight years or more. On being informed of the nature of the case, and that there was nothing for it but a cutting operation, she trembled all over; but I found that the trembling was not caused by the thoughts of the operation; it was at the thoughts of having to take chloroform, from the effects of which, like "Lady Oswald," she might never recover. On making further inquiry as to the origin of her fears, she told me that she had "read a tale called 'Oswald Cray' in Good Words; that the very name of the work and of the editor were sufficient guarantees of the truth, or at least of the correctness of the story; and that it had so deeply impressed her of the dangers of taking chloroform, particularly from those who boasted of having great confidence in the agent, that she would rather postpone the operation until she could make up her mind." After a lapse of six weeks, and by dint of occasional reasoning with her and her friends, I prevailed on her at last to consent to be operated upon under chloroform. On January 10th last, I put her under chloroform and incised the fistula, without the assistance of any one but her nurse (my patient objecting to the presence of a stranger). The patient made a rapid and most satisfactory recovery, and is now as great an advocate for chloroform as she was previously the reverse.

Add to the above the following scene, also the fruits of Good Words. Shortly before I entered the house of my patient, her clergyman, a believer in Good Words, made his exit; and, immediately before inhaling the dreaded chloroform, she begged that her step-child might be brought to her bedside, "that she might kiss her, probably for the last time." I do not make these remarks in derision of the beautiful motives which dictated the actions, but merely to show the state of mind produced in my patient by the perusal of that nonsensical and far fetched scene described in Good Words.

I have only to add, that centuries may elapse before Good Words produces as much real temporal good to humanity, as chloroform has already accomplished in sixteen or seventeen years.

\section{ILLUSTRATIONS OF THE DIFFERENT FORMS OF INSANITY.}

By W. H. O. SANkex, M.D.Lond., Proprietor of Sandywell Park Private Asylum; Lecturer on Mental Disease in University College, London; late Medical Superintendent of the Female Department, Hanwell Asylum.

[Continued from page 13\%.]

THe next illustrations will be of cases of General Paresis. This term has been proposed in the place of "general paralysis", to which there is this fundamental objection, that, in the ordinary acceptation of that term, such a state would be equivalent to death. To avoid this absurdity, it was proposed to insert the word "incomplete". The name then becomes long, and is still inexact; and, moreover, does not separate those diseases with from those without insanity.

By "general paresis of the insane" is meant a peculiar form of mental disease, very common in asylums, having peculiar and well marked characters, and attended with mental unsoundness. And it must be distinguished from a general paralysis met with from spinal disease, and from the state produced by spirit-poisoning or alcoholism.

The scope of these papers does not admit of a discussion on abstract questions of pathology. It may be, however, stated that the French specialists consider that general paresis is a peculiar form or a distinct species of cerebral disease. To this opinion my own experience also leads; though I consider that those writers who view the paralysis as a mere epiphenomenon engrafted upon a case of insanity, or a mere complication or mode of termination of the disease, form a large majority of pathologists generally. I consider one cause of this difference of opinion to arise in a want of clear definition of the cases which are included in the term. There are examples of motor paralysis, undoubtedly, as from spinal disease, or even from cerebral disease, in various' kinds of cases of insanity; and these are, as it were, accidents, not attributes, of this affection; and such accidents occur as one of the sequels of cerebral mischief, resulting from disorganisation of the nervous tissues. Such paralysis occurs in the asylums in all forms ; as local-circumscribed; as hemiplegia, or paraplegia. Necessarily, these grave complications occur towards the end of the disease ; for they contribute to the termination of life. But they occur also after various periods of the attack-sometimes in cases of very long standing, and in conjunction with various other symptoms, as in epileptic mania, in melancholy, or mania; or when the patient has passed into a state of dementia.

The disease meant by the writers on general paresis is different. It has its peculiar mode of attack, its peculiar progress and duration. The phenomena occur in a given order; though of course, as in all disease, the individual cases present certain variations.

The following cases are selected as typical examples of general paresis.

The first case is condensed from the reports, which extend over a period of two years and five months, with comments interspersed. The duration of this case is a fair average of the disease.

E. E. was admitted on November 17 th, 1859 , during my absence from the asylum. The history was gathered from her husband by my assistant. She was 33 years of age, married; the wife of a policeman; of plain education. She never had any children. The present was the first attack. There was

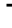


no hereditary tendency to insanity. She had always been temperate.

About four weeks prior to admission, she began to covet articles of luxury beyond her station; as dress and finery. She expressed a wish to ride in a carriage and six horses, and live in the pomp and splendour of a queen. She talked very largely; was restless and troublesome ; excited, hasty, and altered in behaviour. She attempted to escape out of the house.

At the end of the week after admission, her case was reported to the commissioners thus: "Is labouring under acute mania, with exalted ideas; is noisy, garrulous, and destructive."

It may be here pointed out that my assistant, who had had some experience in the disease, makes no allusion to any previous melancholic stage. I take this to be pretty conclusive that none existed; for, though the notes are not by me, they came under my observation; and my attention had already been strongly directed to the first symptoms of general paresis. The notes at first are few and brief, owing to the work imposed by my own absence; but the patient's mental state is pretty clearly indicated by the terms used-“Is labouring under acute mania" -which is only in accordance with received views, that mania may terminate in paresis.

She continued in an excited and maniacal condition; being reported to be, at different times, noisy and destructive to her clothes, from admission up to December 17th, or for one month. Her violence caused her to be placed in seclusion for three hours on November 25th; three hours on the 26th; four hours on the 28th; for two hours on the 29th; for four hours on Dec. 1st; for two hours on Dec. 2nd; for one hour on the 7 th ; for two hours on the 11th; for one hour on the 12th ; and on the 17th, it was reported that she had become quieter, and had requested to go to the laundry to work. She continued to work at the laundry industriously. On January 10th, she had a slight accession of excitement, which was allayed by an opiate. On January 23rd, it is reported : "Is now at work in the laundry; but is subject to occasional outbreaks of excitement, lasting only a short time; and manifesting only a little self-will and perversity of temper." She continued to progress favourably, and became quiet and rational, and, to an inexperienced eye, convalescent.

On April 20th, she was visited by her husband, who said "that he had been conversing with his wife for some time, and had found her perfectly sane and rational. He had never seen her so well in his life." This is quite what is usual; and very frequently the relatives set up their judgments against the medical adviser, and remove the patient from treatment. Many cases are thus lost sight of; and the patient is frequently kept at home for periods varying from months to one or two years; and not unfrequently, on readmission, are reported as cases of a second attack. A fallacy is thus introduced-that the primary attack may be mania, and that general paresis occurs in second attacks. I have pointed this out elsewhere (Journal of Mental Science, No. 48, Jan. 1864), where I have also shown that, out of sixty-one cases treated by me, not one occurred in a genuine second attack of insanity; but that five cases had been reported to be cases of second attack, which proved only to be cases in which a remission of the symptoms had taken place. I am disposed to believe that such remission of maniacal symptoms occurs generally in that proportion, or in five out of sixtyone cases.

The various modes in which the remission occurs have been studied especially by M. le Dr. Sauze (Ann. Médico-Psychol., Oct. 1858).

Whether the symptoms ever are actually absent in these reported remissions may be a matter of doubt. In the present case, the husband, who may represent the public, could detect no disease or change. This patient was examined specially by one or two medical friends, who pronounced her convalescent. To my eye, however, certain indications of the disease were evident; but I failed to convince or demonstrate their existence to the professional friends.

The symptoms or signs present at this period consisted in a peculiar facial expression. As the diagnosis at this stage is important, it may be here described. At first, the peculiarity is but slightly marked; but is of the same kind as when the disease is more advanced. The face then becomes an expressionless mask; the facial muscles partake all equally of the imperfect action; and the delicate lines and folds into which the facial muscles throw the integuments of the face, under the influence of the various emotions of the mind, are lost, or are formed clumsily and imperfectly. When the muscles act, the face is contorted; and when they are at rest, it is void of all expression. The cheeks are flabby and sleek; the mouth is straight; the levatores palpebrarum slightly let fall the eyelid, while the brow is raised or arched; and these two actions, which do not harmonise in health, give a special expression to the face-an expression, however, which is seen in drunkenness. Indeed, since drunkenness affects the muscles generally by impairing their action, many of the symptoms of the one state resemble those of the other.

It was a slight indication of this peculiar expression, coupled with the exalted notions at the commencement of the attack, that directed me to an unfavourable diagnosis.

Nov. 21st, 1s60. General paresis, which had been gradually increasing for some time, was now very marked.

Aug. 19th, 1861. She was in good bodily condition, but feeble health. She took her food well, eating more than others. Catamenia regular. She was very tottering in her gait, and with difficulty went up and down stairs. She was often confused in her articulation, and indistinct; was slightly peevish, and would occasionally strike.

September. Articulation was more indistinct, stammering, and tremulous. She worked regularly at her needle, but performed her work rather more coarsely, and was slower.

Oct. 8th. The conjunctivæ were injected; pupils equal.

Nov. 1st. The mind was becoming more feeble; the voice more tremulous ; pupils equal. The tongue was protruded without difficulty.

December. She was removed to the infirmary, on account of the increasing paralytic symptoms. She had been gradualiy becoming more feeble and tottering in her gait, and more imbecile in mind. Articulation was less distinct. The tongue was free from tremor. The right pupil was a shade larger than the left. Her expression was dull and without animation. The eyebrows were slightly elevated. She bad a difficulty in pronouncing the letter " $r$ " in rural; much contortion was produced in attempting it at the angles of the mouth and chin. The mind was very feeble. She could not say whether it was winter or summer.

Jan. 14th, 1862. Paresis and dementia were increasing. Paretic symptoms were worse in the morning. She gained strength as the day advanced. There was no difference of muscular power between the right and the left side.

Jan. 23rd. She was now very feeble, but had not lost flesh; sat with the head hung down; and rested 
with her elbows cn the chair, in an attitude of great prostration. On her attempting to move, considerable muscular agitation and trembling took place. The features were relaxed, heavy, and expressionless; the pupils were equal ; the conjunctivæ were injected, and discharging thick mucus. She took little notice of what was passing. When she looked up, the eyelids drooped. The brow was arched. In speaking, the voice trembled; and there was considerable twitching of the lips and chin. She said she was "very well and very happy". Her appetite was good.

Feb. 3rd. She took to bed, being unable at last to stand. Pulse 72; no emaciation.

Feb. 6th. She began to play with the bedclothes. Dementia was increasing; sensation was generally appearing dull. She did not evince the least pain when pinched; tickling the soles of the feet produced only slight movement. (This last has been proposed as a diagnostic sign between spinal and cerebral disease; but the evidence appears to be equivocal.)

Feb. 19th. There was slight improvement in strength and mind; and variation in the state of the pupils.

March 3rd. Both pupils were dilated, and slightly irregular in contour.

April 11th. The mind continued to be slightly improved. Her general powers were failing. The pupils varied. Breathing was quick, with slight rhonchus. At intervals she gathered up the bedclothes.

April 12th. She died.

[To be continued.]

\section{NOTES ON HERNIA.}

By Јонм Thompson, M.D., F.R.C.S., Bideford.

$$
\text { [Continued from page } 546 \text { of last volunbe.] }
$$

BEFore applying the taxis, every surgeon endeavours to assure himself of the species of rupture which is the subject of strangulation, and the precise course the protrusion has taken. A hint may not be out of place that, to carry out this intention the more effectively, it is well to use the sense of sight as well as that of touch. Herniæ of different species sometimes resemble each other very closely; and a femoral, tilted by the superficial epigastric vessels over and above Poupart's ligament, may, especially in a female, be confounded with an inguinal, and so the taxis be applied with disastrous effect.

I have, in more than one instance, seen a first and erroneous impression conveyed by the touch, corrected, when, by the eye, the position of the tumour has been examined in relation to the processes of the ilium and os pubis, and the course of the connecting ligament. In the case of ladies, a surgeon often feels some hesitation in proposing an examination by the sight; but where so serious a disease exists, delicacy of feeling must give way to considerations affecting the welfare of the patient and the reputation of the surgeon.

As aids to the taxis, I have used, in almost every case where required, the warm bath, and esteem it beyond all other remedies. I have sometimes bled with benefit; and in two cases had the patients suspended by the legs, in the manner described by Mr. Griffin, but the latter was without advantage. I have never used sufflation; but have tried the injection of cold water for the distension of the bowel, much on the same principle that injected air is supposed to act, but without success. I have little experience of chloroform. Topical applications of cold water have never seemed to me of any avail in femoral; but $I$ have, in two or three cases, known them succeed in old inguinal herniæ, where continued for a long time, the patient being at the same time laid in a favourable position in bed.

The taxis, as used by the surgeons with whom I have acted, as well as by myself, has never resulted in any harm; where unsuccessful, no prejudice has been done to the cutting operation; and where reduction has been accomplished, the health of the patient has promptly returned, unless, by the long continuance of the strangulation, peritonitis had previously come on, and then recovery was not so speedy.

A curious case once occurred in my practice, in a man who was a bootmaker and small farmer. $\mathrm{He}$ was the subject of inguinal hernia, which became strangulated, and he sent for me. I was unable at first to reduce it, and had to employ bleeding to faintness, when I completely succeeded. The man felt immediate relief and restoration. After due tarry with the patient, I left. Next day he prudently remained in bed; but having a good appetite, and knowing that some fresh pork had been obtained for the household, he requested to have some steaks for dinner, which were accordingly cooked and brought to him. He ate freely and with relish, and proposed to have some sleep after. In the course of some hours, as the bedroom seemed very quiet, the wife went upstairs to see how her husband was, and, to her astonishment, she found him quite dead. I got no post mortem examination in the case ; but if $I$ had, my attention would have been directed to the head rather than the abdomen, as the man had suffered some while before from ocular spectra and illusions, dependent, as the event seemed to show, on disease within the encephalon, which, at this particular juncture had resulted in death ; the family, however, connected the hernia more closely with the result, and talking people intimated that the doctor probably did not thoroughly understand the complaint he treated.

Obstruction in old irreducible herniæ occasionally occurs, attended with symptoms resembling those of strangulation, although no additional protrusion has taken place. Several symptoms have been laid down as diagnostic in this condition; and $\mathrm{Mr}$. Erichsen has remarked that, "where obstruction occurs in an old irreducible hernia, vomiting is not feculent." I, however, met with a case where vomiting much resembled that in truly strangulated hernia; and yet no new protrusion had taken place, the mischief having arisen from morbid action set up in an old adherent rupture, the condition of which was verified by an operation.

Sometimes a new protrusion exists with an old irreducible hernia, the strangulation of which is a conndition co-existent with inflammation of the old rupture; in which case, reduction of the strangulated portion may not be attended with complete relief, because the disease in the other portion is not removed at the same time. I have known two cases lately, where the administration of a brisk purgative was attended with complete relief, at the same time that it assured the surgeon of the reduction of the strangulated portion having been effected. It is necessary to use much tact in these instances; for a purgative may otherwise be administered whilst strangulation exists - an undesirable practice, but still one that may occur without a practitioner being fairly chargeable with blame.

In a case of strangulated enterocele in connection with irreducible epiplocele, which came under my advice within the last month, the taxis so much reduced the size of the hernia, that the patient supposed it no larger than usual; and as the symptoms of obstruction were mild, the surgeon hoped they might depend on the morbid action excited in the

\section{更}

号 